\title{
A CONCEPÇÃO DO CONSELHO ESCOLAR SOBRE A GESTÃO DEMOCRÁTICA NO CONTEXTO DA EDUCAÇÃO QUILOMBOLA
}

\author{
Raquel Amorim dos Santos \\ Rosângela Maria de Nazaré Barbosa e Silva \\ Valdecira Carvalho Silva
}

\section{Resumo}

O presente estudo objetivou analisar a concepção do Conselho Escolar sobre gestão democrática no contexto da Educação Escolar Quilombola nas comunidades quilombolas de Jurrussaca e Torres em Tracuateua no Nordeste do Pará. O estudo é uma pesquisa de campo com abordagem qualitativa, dividido em três etapas: fase exploratória, trabalho de campo e análise e tratamento do material empírico e documental. A técnica de coleta foi o questionário semiestruturado. A amostragem foi constituída de 10 (dez) representantes do Conselho Escolar da comunidade quilombola do Jurrussaca e do Torres em Tracuateua-PA. Com Libâneo (2015, 2012), Dourado (2006), Paro (2016) entre outros, nos implicamos na discussão acerca da gestão democrática. Os principais resultados revelam que a concepção do Conselho Escolar sobre gestão democrática na Educação Escolar Quilombola está pautada na busca de mecanismos e condições para que espaços de participação, partilhamento e descentralização do poder ocorram.

Palavras-Chave: conselho escolar; gestão democrática; educação escolar quilombola.

\section{THE SCHOOL COUNCIL'S CONCEP'TION ON DEMOCRATIC ANAGEMENT IN THE CONTEXT OF QUILOMBOLA EDUCATION}

\begin{abstract}
The present study aimed to analyze the concept of the School Council on democratic management in the context of Quilombola School Education in the quilombola communities of Jurrussaca and Torres in Tracuateua in Northeast Pará. The study is a field research with a qualitative approach, divided into three stages: phase exploratory, fieldwork and analysis and treatment of empirical and documentary material. The collection technique was the semi-structured questionnaire. The sample consisted of 10 (ten) representatives of the School Council of the quilombola community of Jurrussaca and Torres in Tracuateua-PA. With Libâneo (2015, 2012), Dourado (2006), Paro (2016) among others, we are involved in the discussion about democratic management. The main results reveal that the School Council's conception of democratic management in Quilombola School Education is based on the search for mechanisms and conditions for spaces of participation, sharing and decentralization of power to occur.
\end{abstract}

Keywords: school council; democratic management; school education quilombola.

\section{LA CONCEPCIÓN DEL CONSEJO ESCOLAR SOBRE LA GESTIÓN DEMOCRÁTICA EN EL CONTEXTO DE LA EDUCACIÓN QUILOMBOLA}

Resumen

Este estudio tuvo como objetivo analizar el concepto del Consejo Escolar sobre gestión democrática en el contexto de la Educación Escolar Quilombola en las comunidades quilombolas de Jurrussaca y Torres en Tracuateua en el Noreste de Pará. El estudio es una investigación de campo con enfoque cualitativo, dividido en tres etapas: fase exploratoria, trabajo de campo y análisis y tratamiento de material empírico y documental. La técnica de recogida fue el cuestionario semiestructurado. La muestra estuvo conformada por 10 (diez) representantes del Consejo Escolar de la comunidad quilombola de Jurrussaca y Torres en Tracuateua-PA. 
Con Libâneo (2015, 2012), Dourado (2006), Paro (2016) entre otros, nos involucramos en la discusión sobre la gestión democrática. Los principales resultados revelan que la concepción del Consejo Escolar de la gestión democrática en la Educación Escolar Quilombola se basa en la búsqueda de mecanismos y condiciones para que se den espacios de participación, reparto y descentralización del poder.

Palabras clave: consejo escolar; gestión democrática; educación escolar quilombola.

\section{INTRODUÇÃO}

Esse estudo analisa a concepção do Conselho Escolar sobre a gestão democrática no contexto da Educação Escolar Quilombola, especificamente nas comunidades quilombolas de Jurussaca $^{1}$ e Torres $^{2}$ em Tracuateua, Nordeste do Pará. A gestão democrática envolve o exercício do poder, processos de planejamento, tomada de decisões, avaliação dos resultados alcançados, entre outros aspectos. Trata-se, portanto, de fortalecer procedimentos de participação das comunidades escolar e local no governo da escola, descentralizando os processos de decisão e dividindo responsabilidades (DOURADO; DUARTE, 2001).

A efetivação da gestão democrática no contexto da Educação Escolar Quilombola, exige também a participação das comunidades quilombolas e suas lideranças. Isso significa a necessidade do diálogo entre a gestão da escola, a coordenação pedagógica e organizações do movimento quilombola nos níveis local, regional e nacional, a fim de que a gestão possa considerar os aspectos históricos, políticos, sociais, culturais e econômicos do universo sociocultural quilombola no qual a escola está inserida (BRASIL, 2012).

Para Dourado (2006, p.13) a democratização da escola implica "[...] repensar em sua organização e gestão, por meio do redimensionamento das formas de escolha do diretor e da articulação e consolidação de outros mecanismos de participação”. Nesse sentido, é fundamental garantir, no "[...] processo de democratização, a construção coletiva do projeto pedagógico, a consolidação dos conselhos escolares e dos grêmios estudantis, entre outros mecanismos". Isso quer dizer que a cultura e a lógica organizacional da escola só se democratizarão se todos que vivenciam seu cotidiano contribuírem para esse processo de mudança.

É preciso mudar a forma de gerir internamente a escola. Portanto, a ideia de gestão democrática se efetivará quando a participação da comunidade nas decisões da escola propiciar condições concretas que atendam de fato suas necessidades (PARO, 2016). Portanto, uma gestão democrática requer o engajamento das pessoas, pois a escola ocupa esse lugar de decisão e mediação.

O tema gestão democrática surgiu das inquietações sobre a Educação Escolar Quilombola ${ }^{3}$ praticada nas comunidades remanescentes de quilombolas de Tracuatuea-PA, em especial no

\footnotetext{
${ }^{1}$ A legalização das terras da Comunidade Quilomobola do Jurussaca (CQJ) remonta desde 11 de junho de 1994 por meio do Intituto de Terras do Pará (ITERPA) que reconheceu o domínio de uma área de terras com ocupação e uso por famílias de remanescentes de quilombos pela Instrução Normativa n ${ }^{\circ}$ 02/1999. E possui a certidão da Fundação Cultural Palmares (FCP) desde 30 de julho de 2013.

2 A Comunidade do Torres que em sua maioria são pessoas do Jurussaca, já implementou a Associação dos Remanescentes de Quilombolas da Comunidade do Torres (ARQUIT), orgão de defesa dos direitos sociais (08/09/2011). As lutas pelos direitos cosntitucionais da comunidade do Torres continua em processo. Enquanto isso a escola Antonio Rosa está sendo reformada e dependente do Conselho Escolar e decisões da Escola Polo.

${ }^{3}$ A educação praticada nestes espaços não é de fato uma Educação Quilombola, é uma educação regular formal, normalmente praticada em qualquer outra comunidade do município, mas inserida dentro de uma comunidade remanescente de quilombolas.
} 
Torres e no Jurussaca. No decorrer da coleta de dados observamos, também, o trabalho desenvolvido pela gestão escolar e percebemos naquele momento que a comunidade do JurusacaPA, possuía Conselho Escolar e tinha autonomia para gerenciar seus recursos, mesmo sendo uma escola anexa sob a administração geral da Escola Polo, Epifânio Melo, situada na Comunidade de Santa Tereza em Tracuateua-PA.

Ampliamos nosso olhar acerca da gestão democrática no contexto da Educação Escolar (que deveria ser Quilombola) desenvolvida na comunidade do Torres-PA. Naquele momento, observamos uma realidade diferente da gestão realizada na escola do Jurussaca-PA, pois naquela, as decisões geralmente eram tomadas de forma hierarquizada, sem a intervenção da comunidade quilombola. A constatação da existência destas distintas realidades, no tocante a gestão democrática, contribuiu para ampliar nosso interesse em pesquisar esses diferentes contextos, especialmente a concepção do Conselho Escolar sobre a gestão democrática na Educação Escolar desenvolvida nas Comunidades Remanescentes de Quilombola em Tracuateua-PA.

Nesse estudo comunidades remanescentes de quilombos são compreendidas como grupos étnico-raciais definidos por auto atribuição, com trajetória histórica própria, dotados de relações territoriais específicas, com presunção de ancestralidade negra relacionada com a resistência à opressão do passado escravista (desigualdade racial junto com desigualdade econômica etc.).

Igualmente, é importante considerar que estas comunidades são grupos que passaram a contar com um reconhecimento oficial de sua cultura e identidade, porém, continuam em conflitos fundiários o que nos remete a um passado associado às lutas por suas terras. A forma de se relacionar com a terra, a produção coletiva, as relações sociais comunais e a valorização de traços sociais culturais ressaltam a importância da categoria território a esses sujeitos impregnados de significações identitárias (FURTADO; PEDROZA; ALVES, 2014).

As Diretrizes Curriculares Nacionais para a Educação Escolar Quilombola (DCNEEQ) estabelecem que a Educação Escolar Quilombola compreende escolas localizadas em territórios quilombolas e escolas que atendem estudantes oriundos de territórios quilombolas. Essa modalidade de ensino se fundamenta e se alimenta da memória coletiva, das línguas reminiscentes, dos marcos civilizatórios, das práticas culturais, das tecnologias e formas de produção do trabalho, dos acervos e repertórios orais, dos festejos, usos, tradições e demais elementos, como a territorialidade, que conformam o patrimônio cultural das comunidades remanescentes de quilombolas de todo o país.

Nesse contexto de uma educação diferenciada - ou pelo menos que deveria ser direcionada para remanescentes de quilombos em suas mais variadas formas de produção cultural, social, política e econômica é necessário pensar a gestão escolar voltada para a transformação social, contrapondo-se à centralização do poder na instituição e nas demais organizações, primando pela participação dos estudantes, funcionários, professores, pais e comunidade local na gestão da escola (DOURADO, 2006).

Para Libâneo (2012) as organizações escolares se caracterizam como unidades sociais em que se destacam a interação entre pessoas e sua participação ativa na formulação de objetivos e de modos de funcionamento da comunidade escolar, portanto é necessário considerar os aspectos informais da organização escolar que dizem respeito a sua cultura organizacional particular.

Os indivíduos são marcados por suas vivências fora dos espaços institucionalizados, em que estão se relacionando a todo momento e o aspecto cultural é esse lugar que constitui o contexto simbólico que rodeia os sujeitos, formando suas subjetividades. A escola, no processo de gestão, deve considerar os aspectos culturais, pois a realidade de cada comunidade incita a uma reflexão do real papel da escola em não apenas de se reger por "[...] diretrizes, normas, procedimentos operacionais e rotinas administrativas que identificam a escola, há aspectos de natureza cultural que 
as diferenciam uma das outras, não sendo a maior parte deles nem claramente perceptível, nem explícita" (LIBÂNEO, 2012, p. 441).

A Constituição Federal de 1988 (CF/88), no artigo 5, estabelece que "Todos são iguais perante a lei". Isso trouxe o reconhecimento das pluralidades étnicas, sociais e culturais desses povos que tem direito a terra e a preservação de seu legado cultural. Também reafirmado na Convenção da Organização Internacional do Trabalho (OIT), que demonstra de fato a existência dessa diversidade cultural e aponta que suas formas de vida precisam ser respeitadas.

$\mathrm{Na}$ prática, ainda há uma marca muito forte na sociedade brasileira que diz respeito às desigualdades sociais e a má distribuição de renda no país, principalmente no que se refere ao acesso à educação, fator que faz da população negra, dentre todas, a mais afetada pela exclusão por causa do racismo, do preconceito e da discriminação. Daí a necessidade de suas lideranças se articularem para pressionar o Estado em efetivar políticas de açôes afirmativas ${ }^{4}$ que contemplem suas necessidades.

A regulamentação que alterou a Lei de Diretrizes e Bases da Educação Nacional (LDB) no 9.394/96, trazida inicialmente pela Lei $10.639 / 03^{5}$, e posteriormente pela Lei $11.645 / 08$, buscou cumprir o estabelecido na $\mathrm{CF} / 88$ - que por seu turno foi fruto de décadas de pressão, luta e reivindicações dos movimentos sociais negros - prevê a obrigatoriedade de políticas universais comprometidas com a garantia do direito à educação de qualidade para todos. Isto significa o reconhecimento da importância da questão do combate ao preconceito, ao racismo e à discriminação na agenda brasileira de redução das desigualdades (BRASIL, 2009).

O processo de gestão democrática da escola deve considerar a legislação que dá visibilidade as matrizes culturais africanas e afro-brasileiras. Nesse sentido, é importante "o diálogo entre a gestão da escola, coordenação pedagógica e organizações do movimento quilombola nos níveis local, regional e nacional", a fim de que a gestão possa considerar os aspectos históricos, políticos, sociais, culturais e econômicos do universo sociocultural quilombola no qual a escola está inserida (BRASIL, 2013).

Segundo as DCNEEQ (BRASIL, 2012) o ponto de partida para a conquista da autonomia pela instituição educacional tem por base a "construção da identidade de cada escola", cuja manifestação se expressa no seu Projeto Pedagógico e no regimento escolar próprio, enquanto manifestação de seu ideal de educação e que permite uma nova e democrática ordenação pedagógica das relações escolares. O Projeto Político Pedagógico (PPP) deve, pois, ser assumido pela comunidade educativa, ao mesmo tempo, como sua força indutora do processo participativo na instituição e como um dos instrumentos de conciliação das diferenças, de busca da construção de responsabilidade compartilhada por todos os membros integrantes da comunidade escolar,

\footnotetext{
4 As ações afirmativas se definem como políticas públicas (e privadas) voltadas à concretização do princípio constitucional da igualdade material e à neutralização dos efeitos da discriminação racial, de gênero, de idade, de origem nacional e de compleição física. Impostas ou sugeridas pelo Estado, por seus entes vinculados e até mesmo por entidades puramente privadas, elas visam a combater não somente as manifestações flagrantes de discriminação, mas também a discriminação de fato, de fundo cultural, estrutural, enraizada na sociedade. De cunho pedagógico e não raramente impregnadas de um caráter de exemplaridade, têm como meta, também, o engendramento de transformações culturais e sociais relevantes, aptas a inculcar nos atores sociais a utilidade e a necessidade da observância dos princípios do pluralismo e da diversidade nas mais diversas esferas do convívio humano (GOMES; SILVA, 2003).

${ }^{5}$ A Lei 10.639/03 e, posteriormente, a Lei 11.645/08, que dá a mesma orientação quanto à temática indígena, são Leis afirmativas, no sentido de que reconhecem a escola como lugar da formação de cidadãos e afirmam a relevância de a escola promover a necessária valorização das diferentes matrizes culturais que compõem nossa sociedade (BRASIL, 2009).
} 
sujeitos históricos concretos, situados num cenário geopolítico preenchido por situações cotidianas desafiantes.

Diante da necessidade de uma gestão democrática para a Educação Escolar Quilombola nos inquietamos e questionamos: qual a concepção do Conselho Escolar sobre a gestão democrática no contexto da Educação Escolar Quilombola em Tracuateua-PA? Entretanto, é necessário refletir que a nível municipal, inexiste uma "Educação Escolar Quilombola" de fato, haja visto que, em realidade, o que se verifica é apenas a inserção de uma escola "branca", de ensino regular, formal, dito normal, igual a qualquer outra localidade tracuateuense, porém aplicada no seio das comunidades remanescentes de quilombolas do município.

Para coleta de dados, inicialmente, entrou-se em contato com os líderes das comunidades quilombolas, aos quais foram expostas as finalidades do trabalho e solicitado aos mesmos a permissão para a realização do estudo em mãos. Nesse sentido, foi solicitada permissão para a realização da pesquisa nas escolas em foco, com os membros do Conselho Escolar da comunidade Jurussaca e Torres, os quais foram eleitos pelos moradores, pais e ou responsáveis pelos alunos, como representantes da comunidade escolar, assim, responderiam algumas questões chaves referentes à temática do estudo.

Consecutivamente delimitamos o questionário de acordo com as perspectivas da pesquisa, para os seguintes membros: membro nato (Diretora da Escola), Presidente do conselho, tesoureiro, secretario e os membros fiscais. Partimos da premissa de que esta abordagem, particularmente, é a melhor opção para apontar o tipo de gestão que está sendo desenvolvida na comunidade mediante a Educação Escolar Quilombola.

Os dados foram coletados a partir do instrumento questionário, constituído por 10 (dez) questões, previamente elaboradas que ajudaram a traçar perfil dos membros do Conselho Escolar das respectivas escolas ${ }^{6}$. Segundo Severino (2007, p.125), este é considerado como "[...] o conjunto de questões, sistematicamente articuladas, que se destinam a levantar informações escritas por parte dos sujeitos pesquisados, com vista a conhecer a opinião dos mesmos sobre os assuntos em estudo".

Nesse estudo se optou pela abordagem qualitativa que na concepção de Minayo (2010) é um trabalho artesanal que não prescinde da criatividade, realiza-se fundamentalmente por uma linguagem baseada em conceitos, preposições, hipóteses, métodos, e técnicas, linguagem esta que se constrói com um ritmo próprio e particular. O processo científico desse estudo se divide em três etapas: Fase exploratória, trabalho de campo e análise e tratamento do material empírico e documental.

A amostragem desse estudo foi realizada em 02 (duas) escolas situadas nas comunidades remanescente quilombolas de Jurrussaca e Torres, no Nordeste do Pará, a saber: Escola Municipal de Educação Infantil e Ensino Fundamental Prof. Luduvino Antônio de Araújo, situado na Comunidade de Jurussaca e Escola Municipal de Ensino Infantil e Fundamental Antônio Rosa, localizada na Comunidade do Torres.

A Escola Municipal de Educação Infantil e Ensino Fundamental Prof. Luduvino Antônio de Araújo, possui 50 alunos, sendo 17 da Educação Infantil e 33 do Ensino Fundamental. Possui 02 (dois) banheiros, sendo um feminino e outro masculino, 01(uma) cozinha, 01 (um) depósito e um pátio para a funcionária responsável pela manutenção da escola fazer seus trabalhos diários, ainda possui água de poço artesiano. A escola conta com Conselho Escolar que é representado por

\footnotetext{
${ }^{6}$ Explique-se que a Escola Antônio Rosa, da Comunidade do Torres, de fato não possui Conselho Escolar próprio, pois a legislação prevê número mínimo de 50 alunos para permitir a criação de tal instituição, quantitativo este que aquela localidade não alcança. Assim sendo, o Conselho Escolar que responde por esta unidade de ensino é o da Escola Polo X, Escola Francisco Nascimento, na Comunidade de Santa Maria.
} 
todos os seguimentos da escola e na questão da gestão, como em toda a rede municipal, a diretora é designada pelo diretor da Escola Polo.

A Escola Municipal Antônio Rosa, localizada na Comunidade do Torres, funcionou, por um tempo, na igreja católica que fica ao lado, pois, o prédio encontra-se em reforma, desde 2016. A escola oferta Educação Infantil e Fundamental nos anos iniciais (Multissérie). No turno da manhã funciona a Educação Infantil e o Ensino Fundamental com um total de 13 alunos (Pré I e II e $1^{\circ}$ ano - Multisserie) e no turno da tarde, os anos iniciais do Ensino Fundamental, com 14 alunos ( $1^{\circ}$ ao $5^{\circ}$ - Multissérie). Em relação ao Conselho Escolar, percebemos nos discursos que a comunidade não participa das decisões, pois, invariavelmente, as reuniões, e, portanto, as decisões, acontecem na escola Polo, localizada na Comunidade de Santa Maria em Tracuateua-PA.

No que se refere à amostragem para o estudo, em número de 10 sujeitos, foram selecionadas de acordo com os seguintes critérios: a) a singularidade da descendência dos sujeitos remanescentes de quilombos; b) a relevância em conhecer a realidade da gestão democrática da Educação Escolar Quilombola; c) e escolas localizadas em comunidades remanescentes de quilombolas que possuem Conselho Escolar.

Pesquisamos os sujeitos que integram o Conselho Escolar das escolas pesquisadas com a finalidade de identificar o perfil identitário e profissional dos sujeitos que compõem esse estudo. Para preservar a identidade dos sujeitos da pesquisa optamos por identificá-los com a letra do alfabeto. Assim, os agentes pesquisados da escola situada na Comunidade de Jurussaca foram identificados com a letra $\mathrm{A}$ e com a letra $\mathrm{B}$ aqueles pertencentes a escola da Comunidade do Torres, conforme especificado abaixo.

Tabela 1: Perfil identitário e profissional dos membros do Conselho Escolar.

\begin{tabular}{|c|c|c|c|c|}
\hline $\begin{array}{c}\text { MEMBRODO } \\
\text { CONSELHO }\end{array}$ & FORMAÇÃO & SEXO & IDADE & $\begin{array}{c}\text { TEMPO DE } \\
\text { TRABALHO }\end{array}$ \\
\hline Gestora A & Pedagogia & F & 41 a 45 anos & Menos de 5 anos \\
\hline Gestora B & Pedagogia & F & 26 a 30 anos & Menos de 5 anos \\
\hline Presidente A & Pedagogia & M & 41 a 45 anos & Mais de 15 anos \\
\hline Tesoureiro A & Pedagogia & F & Mais de 46 anos 40 anos & De 5 a 10 anos \\
\hline Tesoureiro B & Pedagogia & M 15 anos \\
\hline Secretária A & Pedagogia & F & Mais de 46 anos 45 anos & Mais de 15 anos \\
\hline Secretária B & Pedagogia & F & Mais de 46 anos & Mais de 15 anos \\
\hline Conselho Fiscal A & Sociologia & F & 36 a 40 anos & De 5 a 10 anos \\
\hline Conselho Fiscal B & Ens. Fundamental & F & Mais de 46 anos & Mas de 15 anos \\
\hline
\end{tabular}

Fonte: Elaborado pelas autoras com base no Questionário/2018.

Os membros do Conselho Escolar entrevistados apresentam 70\% dos profissionais com formação de nível superior na área de Pedagogia, sendo 10\% em Letras, 10\% Sociologia e 10\% no Ensino Fundamental. Também observamos que a maioria dos membros é do sexo feminino, equivalente a $70 \%$ e 30\% do sexo masculino. O Censo Escolar 2010 confirma a presença de 
mulheres no mercado de trabalho, pois mostrou que em dez anos o nível de instrução das mulheres continuou mais elevado que os dos homens, e consecutivamente elas ganharam mais espaços no mercado de trabalho.

De acordo com esses indicadores há uma variação na idade desses sujeitos, contando com $40 \%$ de profissionais com mais de 46 anos de idade, de 41 a 45 anos 30\%, de 36 a 40 anos 20\% e $10 \%$ entre 25 e 30 anos. Sendo a maioria destes funcionários públicos concursados (efetivos), o que está de acordo com as normas do regimento do Conselho Escolar, com exceção daqueles que são representantes do Conselho Fiscal e membro nato, como a direção da escola. Além disso, $60 \%$ possuem mais de 15 anos de trabalho na comunidade, menos de 5, e de 5 a 10 somam 40\% dos membros do Conselho Escolar. Somados a esses indicadores, também quisemos saber a autoclassificação dos membros do Conselho Escolar.

Tabela 2: Autoclassificação e residência dos membros do Conselho Escolar.

\begin{tabular}{|l|l|l|l|}
\hline $\begin{array}{l}\text { MEMBRO } \\
\text { CONSELHO }\end{array}$ & $\begin{array}{l}\text { AUTOCLASSIFICAÇÃO } \\
\text { RACIAL }\end{array}$ & $\begin{array}{l}\text { REMANESCENTE } \\
\text { QUILOMBO }\end{array}$ & $\begin{array}{l}\text { DE } \\
\text { RESIDE } \\
\text { COMUNIDADE }\end{array}$ \\
\hline Gestora A & Indígena & Não & Não \\
\hline Gestora B & Preta & Não & Não \\
\hline Presidente A & Preto & Sim & Não \\
\hline Presidente B & Pardo & Não & Não \\
\hline Tesoureiro A & Preto & Sim & Sim \\
\hline Tesoureiro B & Preto & Não & Não \\
\hline Secretária A & Preto & Sim & Sim \\
\hline Secretária B & Preto & Não & Não \\
\hline Conselho Fiscal A & Branco & Não & Não \\
\hline Conselho Fiscal B & Branco & Não \\
\hline
\end{tabular}

Fonte: Elaborado pelas autoras com base no Questionário/2018.

Em relação a autoclassificação racial dos membros do Conselho Escolar das Comunidades do Jurussaca e Torres, observamos nas respostas que a maioria se autodeclarou preta (60\%), seguido de branca $(20 \%)$ em segundo lugar, e parda e indígena 10\%. De fato, o percentual dos membros do Conselho Escolar se autodeclarou de cor preta dentro do próprio território quilombola. Mas, há um dado importante, qual seja: apenas 02 (dois) membros do Conselho Escolar residem na Comunidade do Jurussaca, os demais não moram na comunidade e trabalham em sua maioria na sua escola Polo, a Epifâneo Melo que fica na localidade de Santa Tereza (Polo VI). O caso do Torre ainda é pior, pois, sendo seu Polo situado na Comunidade de Santa Maria (Polo X), na comunidade mesmo, não reside nenhum membro daquele conselho. Portanto, depreende-se destes dados que tanto Jurussaca, quanto Torre, são poucos ou quase nada representados por seus moradores dentro dos organogramas dos seus respectivos Conselhos Escolares, ou aqueles que lhe concernem.

As Diretrizes Curriculares Nacionais para a Educação Escolar Quilombola, em um dos seus princípios assegura a presença preferencial de professores e gestores quilombolas nas escolas quilombolas e nas escolas que recebem estudantes oriundos de territórios quilombolas (BRASIL, 2012). Portanto, esse princípio precisa ser considerado na condução de uma gestão diferenciada para povos que historicamente foram estigmatizados.

Para Baile (2016) as tendências de identificação racial, da forma como foram medidas pela autoclassificação racial ou de cor no censo nacional, parecem estar se movendo em direção a um "escurecimento" da população. Essa tendência chega ao nosso território quilombola, como reflexo de empoderamento do homem negro, e sua configuração na sociedade promovendo a valorização étnica no contexto escolar quilombola. 
DOI: $10.12957 /$ teias.2021.52781

Os dados coletados foram analisados a partir dos discursos contidos nas falas dos entrevistados, de modo que as respostas de maior representatividade foram descritas, parcial ou totalmente, para dar fidedignidade à pesquisa. Os dados foram analisados com base na análise dos discursos (AD).

Segundo Orlandi (2001 p. 11) a análise de discurso possibilita de forma efetiva que os leitores se situem melhor no confronto com "[...] a linguagem e, por ela, com o mundo, com os outros sujeitos, com os sentidos, com a história". Ainda aponta que a ideia de uma representação e sua análise delimita muito bem os espaços onde esses sujeitos produzem sua fala, muitas vezes se apropriam do discurso para mascarar realidades e debater sobre as verdadeiras necessidades da comunidade.

A seguir, abordamos sobre o significado de gestão democrática, o processo de escolha da gestão, o papel do Conselho Escolar e quem participa efetivamente desse colegiado.

\section{GESTÃO DEMOCRÁTICA NO CONTEXTO DA EDUCAÇÃO ESCOLAR QUILOMBOLA}

Nesse estudo, partimos do pressuposto de que a gestão democrática na Educação Escolar Quilombola, é um debate suscitado em diversas pesquisas, que buscam compreender como ela foi se estruturando no cenário educacional brasileiro em suas políticas e demandas sociais, principalmente a partir da CF/88, LDB n ${ }^{\circ} 9.394 / 96$ e sua alteração pela Lei $n^{\circ} 10.639 / 03$ e DCNEB (2012). Isso, não significa que as lutas e as perspectivas de mudanças surgem apenas nesse momento de garantia de direitos pela legislação, mas, é um marco das lutas dos negros pelo reconhecimento e valorização de sua contribuição na formação do povo brasileiro.

A CF/88 reconhece a igualdade da população brasileira independente de raça, cor, sexo, gênero e geração. Tal prescrição serviu de base para reformulação de diretrizes que implementassem políticas públicas de ações afirmativas, com vista a reparação e reconhecimento da população negra e seu o papel histórico inquestionável para formação da sociedade brasileira.

E ainda, a Carta Magna ampara a gestão democrática, que foi referendada posteriormente pela LDB no 9.394/96 que, em seu fundamento, está centrado o ensino público que considera a escola como uma instituição autônoma mediante a participação dos pais, funcionários e alunos de acordo com suas realidades. $\mathrm{Na}$ LDB n ${ }^{\circ}$ 9.394/96, a gestão democrática, enquanto princípio aparece no artigo $3^{\circ}$, inciso VIII que estabelece: “Gestão democrática do ensino público, na forma desta Lei e da legislação dos sistemas de ensino". A esse respeito, dispõe o art. 14:

Os sistemas de ensino definirão as normas de gestão democrática do ensino público na educação básica, de acordo com as suas peculiaridades e conforme os seguintes princípios: I - participação dos profissionais da educação na elaboração do projeto político-pedagógico da escola; II - participação das comunidades escolar e local em conselhos escolares ou equivalentes.

Diante ao exposto é assegurado a participação dos profissionais da educação na construção do Projeto Pedagógico da escola, bem como em Conselhos Escolares, sendo este um dos mais importantes mecanismos de democratização da gestão de uma escola, pois quanto mais ativa e ampla for a participação dos membros do Conselho Escolar na vida da escola, maiores serão as possibilidades de fortalecimento dos mecanismos de participação e de decisão coletiva, conforme destaca Dourado (2006). 
Pensar esses princípios implica alterarmos a escola que temos e buscarmos a construção de uma nova escola que seja além de pública, permeada por processos de participação e de gestão participativa, envolvendo a comunidade (professores, coordenadores pedagógicos, funcionários, pais e alunos) nos processos de tomada de decisões, construindo coletivamente a autonomia da escola.

Para Libâneo (2012, p. 450) a gestão escolar pode assumir diferentes concepções podendo ser centralizadora e/ou democrática, consequentemente isso refletirá na atuação da escola e em seu papel social e na formação dos alunos, pois tais concepções podem gerar de um lado uma gestão centralizada e hierarquizada com baixa participação ou outra democrática e participativa nas decisões da escola. Isso significa que "[...] as concepções de gestão escolar refletem diferentes posições".

Na concepção de Libâneo (2015) uma escola na qual a gestão é centralizadora (na mão do diretor), acaba por operar "de cima para baixo" perde sua função democrática. Essa concepção hierarquizada de gestão ainda é praticada pela maioria das escolas, regidas por interesses pessoais ou políticos, alijando os sujeitos envolvidos da participação e das decisões da comunidade escolar, sendo que muitas vezes, esta situação é uma conjuntura dada a partir da própria gestão municipal da rede pública de ensino.

A concepção sociocrítica é apresentada por Libâneo (2015) como a mais adequada para o modelo de gestão, pois esta concepção leva em consideração alguns aspectos fundamentais para uma gestão democrática, diferente das concentradas em estruturas rígidas e hierarquizadas. Nessa concepção leva-se em conta o contexto social, cultural e político da comunidade escolar ao qual possibilita a tomada de decisões coletivas, estimulando o diálogo, a reflexão e a autonomia em gerir sobre as reais necessidades e desafios da escola.

A concepção democrática de gestão se efetiva com participação do coletivo, em busca de melhores condições educacionais. A escola passa a ser um espaço democrático participativo, com tomada de posições de seus agentes (gestor, coordenadores pedagógicos, docentes, alunos, pais e/ou responsáveis) frente aos seus objetivos, portanto "[...] a participação é o principal meio de assegurar a gestão democrática, pois possibilita o envolvimento de todos os integrantes da escola no processo de tomada de decisões e funcionamento da organização escolar" (LIBANEO, 2012, p. 450).

O espaço organizacional da escola no tocante a gestão democrática deve atender os princípios da Educação Escolar Quilombola, pois a população quilombola tem direito a uma educação diferenciada, a um currículo flexível e interdisciplinar, bem como a implementação do Conselho Escolar que tem papel decisivo na democratização da educação e da escola, na medida em que reúne diretores, professores, funcionários, estudantes, pais e outros representantes da comunidade para discutir, definir e acompanhar o desenvolvimento do projeto político pedagógico da escola, além acompanhar as ações pedagógicas, administrativas e financeiras, contribuindo para a efetivação da democracia e melhoria da qualidade da educação quilombola.

As DCNEEQ ressaltam que a luta dos movimentos negros pela preservação da sua cultura fez com que questão dos quilombos fosse ficando cada vez mais evidenciada, sobretudo em torno a educação escolar, em específico da elaboração de um currículo que contemplasse e debatesse a situação de invisibilidade do negro na escola (BRASIL, 2013).

Para a efetivação dessas práticas as DCNEEQ apontam a necessidade de gestão democrática e uma estrutura educacional para as comunidades quilombolas que priorize, dentre outros aspectos a presença preferencial de professores e gestores quilombolas nas escolas quilombolas e nas escolas que recebem estudantes oriundos de territórios quilombolas e garantia 
do protagonismo dos estudantes quilombolas nos processos político-pedagógicos em todas as etapas e modalidades $\left(\operatorname{art} .8^{\circ}\right)$.

Paro (2016) assegura a participação da comunidade nas decisões da escola e sua efetiva participação é garantia do exercício de sua cidadania que os direcionem para o "[...] um projeto de democratização" dentro da dinâmica do espaço escolar.

Democratizar a escola ainda é um desafio devido a interesses políticos, pois a manutenção da ideia do diretor como "autoridade máxima" da escola, ainda percorre o imaginário social das escolas básicas, sendo uma estratégia política do Estado para controlar e regular seus interesses.

Paro (2016) faz críticas a esse papel centralizador do diretor que detém todo o poder de decisão em suas mãos. A esse respeito corrobora:

[...] o maior obstáculo que vejo, nos dias de hoje, é precisamente a função atual do diretor que o coloca como autoridade última no interior da escola. Essa regra, astutamente mantida pelo estado, confere o caráter autoritário ao diretor, na medida que estabelece uma hierarquia na qual ele deve ser o chefe que emana todas as ordens na instituição escolar [...] faz com que o diretor tendencialmente busque os interesses dominantes em oposição aos interesses dos dominados; e confere aparência de poder ao diretor que em nada corresponde à realidade concreta (PARO, 2016, p. 16).

A direção é um princípio e atributo da gestão e não um privilégio de alguém, se essa função não mediar essa relação entre escola e a comunidade, certamente dificultará a integração e a obtenção de resultados que beneficiem a comunidade. Paro (2016) considera que esse modelo de gestão é inviável devido à ausência da participação da comunidade nas decisões e tendo apenas o diretor com a palavra final. Não obstante, é preciso combater esse tipo de gestão autoritária, pois "[...] a escola só pode desempenhar um papel transformador se estiver junto com os interessados, se organizar para atender aos interesses das camadas [...] aos quais essa transformação favorece, ou seja, das camadas trabalhadoras" (idem, 2016, p. 17).

Nessa ótica, os processos de gestão da escola vão além da gestão administrativa, eles envolvem ações que procuram estimular a participação de diferentes pessoas e articular aspectos financeiros, pedagógicos e administrativos com vista a promover uma educação de qualidade (DOURADO, 2001) e, “[...] que abranja os processos formativos que se desenvolvem na vida familiar, na convivência humana, no trabalho, nas instituições de ensino e pesquisa, nos movimentos sociais e organizações da sociedade civil e nas manifestações culturais", conforme assegura a LDB n ${ }^{\circ}$ 9.394/96 em seu Art. $1^{\circ}$.

A gestão democrática no contexto da Educação Escolar Quilombola não é diferente, pois mesmo sendo um "[...] processo amplo que inclui a família, a convivência com os outros, as relações de trabalho e com o sagrado e as vivências nas escolas, nos movimentos e as outras organizações da comunidade[...]" (COELHO et al, 2015, p. 117), é imprescindível ações compartilhadas na escola com vista a fortalecer os processos democráticos de gestão e o sentido de existência do legado da população negra no contexto da escola.

Para Dourado (2001) o processo democrático de gestão envolve o exercício do poder, incluindo os processos de planejamento, a tomada de decisões e a avaliação dos resultados alcançados. Trata-se, portanto, de fortalecer procedimentos de participação das comunidades escolar e local no governo da escola, descentralizando os processos de decisão e dividindo responsabilidades.

A gestão democrática no contexto da Educação Escolar Quilombola constitui-se a partir das lutas dos movimentos sociais identitários por melhorias, contribuindo para descortinar a discriminação existente nas escolas. Nesse sentido, a conquista da participação efetiva do diretor, 
DOI: $10.12957 /$ teias.2021.52781

coordenador, alunos, pais e funcionários da comunidade quilombola viabiliza a democratização da gestão no ambiente escolar, que passa a enfrentar os novos desafios da atualidade causando mudanças profundas, no currículo escolar, nos livros didáticos, formação de professores e a própria organização cultural da escola, pois, os novos tempos exigem mudanças de pensamento, a respeito da escola em território quilombola.

Nessa ótica, durante a pesquisa foram feitas perguntas, por meio do questionário relacionado à gestão democrática, onde a maioria conceituou em poucas palavras e de forma simples o significado gestão demócratica. A esse respeito o Conselho Escolar revela:

Eu entendo que devemos chamar mais os pais para participarem dos eventos escolares na comunidade (PRESIDENTE A, Questionário, 2018).

Entendo que a gestão seja aquela em que toda a comunidade escolar, tem vez e voz e tem total transparência ,no gerenciamento de recursos e a participação de todos. (PRESIDENTE B, Questionário, 2018).

A gestão democrática é a melhor forma de se trabalhar em uma instituição, pois, na gestão democrática se trabalha em equipe com a participação de todos (SECRETARIA B, Questionário, 2018).

A gestão democrática na escola permite a participação de diversos seguimentos da comunidade escolar: professores, pais, estudantes, funcionários, lideranças comunitárias na construção de projetos e processos escolar (DIRETORA B, Questionário, 2018).

Para os membros do Conselho Escolar os discursos, mais expressivos, revelam que o significado da gestão demócratica é expressado pela participação dos pais, da comunidade escolar, transparência na gestão dos recursos públicos, trabalho em equipe, decisões coletivas e descentralização do processo de gestão escolar e significativamente a participação das lideranças comunitárias na construção de projetos escolares, que contribuem para o fortalecimento do Conselho Escolar.

Nas discussões sobre gestão demócratica com base em Paro (2016), Libâneo (2012) e Dourado (2006) a gestão democrática só se efetiva com a coletividade, participação e decisão de todos os envolvidos como: Diretores, coordenares, professores, alunos e comunidade com o poder de decisão para além dos muros da escola. Contudo, nos discursos dos entrevistados é possível perceber que a participação da comunidade escolar como um processo democrático viabiliza a ação democrática idealizada.

Para Libâneo (2012) a perspectiva da gestão democrática é atividade coletiva que implica a participação de objetivos comuns, por outro, depende também de capacidades e responsabilidades individuais e de uma ação coordenada e controlada. Para isso, valoriza os elementos internos do processo organizacional como a participação, o dialógo, a discussão coletiva e autonomia que são práticas da gestão democrática. Assim, possibilitando aos sujeitos da escola adentrar nesse mundo administrativo e pedagógico, considerando suas singularidades.

Nesse processo democrático, o diretor passa a ser um líder cooperativo, articulando as ideias e expectativas da comunidade, com visão de conjunto nos aspectos pedagógicos e administrativos, financeiros e culturais. A gestão democrática segundo os preceitos legais deve ficar atenta a realidade histórica, social, econômica, cultural e ambiental da comunidade onde a escola está situada e o público alvo que a escola recebe em seu espaço de ensino com vista a garantir seus direitos de cidadania.

Essa é uma questão que precisa ser levada a sério pelos educadores e formuladores de políticas educacionais (CAVALEIRO; GOMES, 2001). De todo modo, a sensibilidade da gestão democrática em conhecer os sujeitos da escola e suas diferenças torna-se imperativo para a 
transformação da escola em um território de equidade e respeito, um espaço adequedo a formação do cidadão.

Pensar as diferenças no espaço escolar é compreendermos as diferentes realidades das escolas brasileiras, sobretudo aquelas situadas em território quilombola, as quais são orientadas a se desenvolver em unidades educacionais inscritas em suas culturas, requerendo pedagogia própria, que denominamos, nesse estudo de Pedagogia do Quilombo em respeito as suas especificidades étnicocultural, o direito de se apropriar dos conhecimentos tradicionais e das suas formas de produção de modo a contribuir para seu reconhecimento, valorização e continuidade à tradição de sua ancestralidade.

É uma pedagogia que emerge da comunidade e, a partir dos conhecimentos produzidos por ela, tem a força de transformar a escola por meio da gestão democrática. Isso ocorre quando a escola compreende, em todos os sentidos, que o território em que está situada faz parte de um acervo dinâmico do patrimônio material e imaterial da cultura negra no Brasil, em que o fator preponderante é a questão étnica.

A gestão democrática no contexto da Educação Escolar Quilombola nos possibilita refletir sobre o papel do Conselho Escolar que passa ser fundamental para o processo de discussão nas comunidades escolares, com ações conjuntas e corresponsabilidade de todos no processo educativo. É nesse contexto que surge o Conselho Escolar como uma das diretrizes das políticas de descentralização da educação.

O Conselho Escolar precisa realizar ações conjuntas com a gestão da escola, que é membro nato, com vista à qualidade da escola básica. Nesse sentido, as políticas públicas para a educação do campo no sentido de melhoria arquitetônica da escola, apoio técnico e financeiro, entre outros aspectos contribuem para ações coletivas visando a unidade da escola.

A construção da gestão democrática necessita ser um processo de aprendizagem coletiva, pois as decisões não devem ser apenas de forma mecânica, isso pode levar a gestão ao fracasso escolar. Todos devem participar, a autonomia escolar, requer muita luta, dedicação, sobretudo daqueles que estão inseridos nos processos educativos.

Assim, quando se fala em autonomia, defende-se que:

[...] a comunidade escolar tenha um grau de independência e liberdade para coletivamente pensar, discutir, planejar, construir e executar seu projeto político pedagógico, entendendo que neste está contido o projeto de educação ou de escola que a comunidade almeja, bem como estabelecer os processos de participação no dia-a-dia da escola (BRASIL, 2004, p. 47).

A comunidade escolar atua em sintonia com a administração da escola e define caminhos para tomar decisões administrativas, financeiras e político-pedagógicas condizentes e contribui para o processo de construção do Projeto Político-pedagógico e a participação dos diversos segmentos escolares. Para tanto, os espaços de participação nas decisões da escola devem ser ampliados cada vez mais, seja no processo de escolha de dirigentes, seja nas deliberações acerca das questões financeiras, pedagógicas e administrativas (GRACINDO, 2007).

O Conselho Escolar ao ser questionado sobre como se dá o processo de escolha da gestão escolar afirma:

Quem determina a gestão escolar é a SEMED (MEMBRO FISCAL A, Questionário, 2018.).

O Diretor da escola Sede é quem escolhe a responsável de nossa escola (SECRETÁRIA, Questionário 2018).

Indicação feita pelos governantes (SECRETÁRIA B, Questionário 2018). 
O Diretor da escola sede que escolhe, para resolver as problemáticas acentuadas entre os funcionários (DIRETORA A, Questionário 2018).

Nos discursos do Conselho Escolar percebe-se que a escolha do diretor da escola se dá por "indicação", muitas vezes demadada pela Secretaria Municipal de Educação (SEMED), ou pela Diretora da Escola Polo, ou ainda em casos mais extremos, pelos próprios governantes. Isso se distancia dos objetivos de uma gestão democrática. Assim, percebemos que as escolas pesquisadas não apresentam autonomia para a escolha de seus dirigentes, nem se percebe a intervenção do Conselho Escolar no processo de escolha da gestão. Ou seja, nos casos estudados e no contexto onde estão inseridos, invariavelmente o cargo de gestão escolar é imposto.

Nesse sentido, Gracindo (2007, p.34) corroboram:

A escolha democrática dos dirigentes escolares e a consolidação da autonomia das escolas alinham-se aos colegiados com a finalidade de desvendar os espaços de contradições gerados pelas novas formas de articulação dos interesses sociais. A partir do conhecimento destes espaços, certamente presentes no cotidiano da vida escolar e das comunidades, é que será possível ter os elementos para a proposição e construção de um projeto educacional inclusivo.

Essas políticas públicas, entendidas como ações estabelecidas para a transformação da realidade, certamente sinalizarão o caminho da construção de uma sociedade inclusiva, em que a educação, para ser um dos alicerces da cidadania, precisa ser necessariamente, democrática e de qualidade.

Percebe-se que na realidade das comunidades quilombolas pesquisadas isso se distancia ainda mais pela dificuldade de implementação da Lei $n^{\circ}$ 10.639/2003 e das diretrizes que regem a educação quilombola. Além disso, a integração que devia ser desenvolvida encontra entraves políticos para sua aplicação, fazendo com que a comunidade fique excluída desse ambiente que devia ser de participação democrática. Assim, a relação escola/comunidade fica enfraquecida em seus diferentes aspectos, sejam no aspecto administrativo, pedagógico e financeiro.

O Conselho Escolar passa a ser o órgão máximo da gestão democrática, pois as tomadas de decisões realizadas no interior da escola são ordenadas pelos membros representantes da comunidade escolar. Assim, cada Conselho Escolar tem suas ações respaldadas pelo próprio estatuto, que determina a quantidade de membros, promove reuniões e determina o processo de renovação dos conselheiros.

Nesse sentido, questionamos qual o papel do Conselho Escolar e quem efetivamente participa. As respostas mais expressivas revelam:

É lutar pela melhoria da escola e comunidade (MEMBRO FISCAL A, Questionário, 2018).

Desenvolver mais atividades escolares para os pais. O Conselho Escolar é composto de funcionários efetivos e pais da comunidade (PRESIDENTE B, Questionário, 2018).

Gerenciar os recursos que vem para a escola, professores e pais da escola (SECRETARIA A, Questionário, 2018).

Gerenciar os recursos e diologar com a comunidade escolar sobre as problemáticas da escola para resolver a situação, com a participação dos professores e os pais (TESOUREIRO A, Questionário, 2018).

Os membros do Conselho Escolar das comunidades pesquisadas reconhecem o papel do Conselho, sobretudo a luta por melhorias da comunidade escolar e local, participação dos representantes da escola, bem como o gerenciamento e transparência dos recursos que as escolas 
recebem. Nos discursos do Conselho Escolar também foi possível perceber que os agentes que participam efetivamente desse órgão colegiado são os pais, professores e funcionários efetivos, os quais participam da escolha dos membros do Conselho Escolar. Nesse sentido, é importante a representatividade, a disponibilidade e o compromisso. É necessário também saber ouvir e dialogar, assumindo a responsabilidade de acatar e representar as decisões da maioria, sem nunca desistir e apresentar as suas propostas, pois o Conselho Escolar é um espaço de participação e, portanto, de exercício de liberdade (BRASIL, 2004).

\section{CONSIDERAÇÕES FINAIS}

Podemos constatar que houve avanços nas políticas públicas em relação a educação da população negra no Brasil, que de fato ainda tem que lutar pela sua afirmação. Os resultados da pesquisa revelam que na concepção do Conselho Escolar a gestão democrática na Educação Escolar Quilombola, existe por meio da participação da escola e comunidade, construção de projetos, transparência na gestão e recursos públicos, decisões coletivas e descentralizadora com a participação ativa de todos. Cabe também ressaltar que a democratização para a escolha do gestor escolar perpassa pela dificuldade de se realizar devido as relações de poder no âmbito da administração municipal, ficando, portanto, a escola sem autonomia, pois, o responsável pela unidade anexa, subordina-se ao diretor da Escola Polo, indicado pela SEMED.

A gestão democrática na concepção do Conselho Escolar apresenta fragilidades em relação ao Projeto Político Pedagógico da Educação Escolar Quilombola, uma vez que as escolas não possuem o PPP, ou quando existe não se tem interesse, sobretudo em relação a participação dos alunos e da coordenação que não o exige. Também foi possível perceber que as atividades que envolvem participação nas escolas quilombolas são pontuais, pautadas em datas comemorativas, reuniões e atividades com os pais.

Assim, a gestão democrática no contexto da Educação Escolar Quilombola em Tracuateua$\mathrm{PA}$, existe mais ainda está muito distante das necessidades das comunidades quilombolas. É necessária uma aproximação atuante da escola com a comunidade, promovendo diálogos sobre as problemáticas da escola nos eixos: pedagógico, administrativo e financeiro, visando o fortalecimento do vínculo afetivo, familiar, territorial, histórico, cultural e religioso, ressaltando os aspectos do legado africano, para solidificar a identidade quilombola ampliando o exercício da cidadania.

Concluímos que a concepção do Conselho Escolar sobre gestão democrática na Educação Escolar Quilombola está pautada na busca de mecanismos e condições para que espaços de participação, partilhamento e descentralização do poder ocorram. A pesquisa demonstra a urgência de elaboração e implementação do Projeto Político Pedagógico da escola e eleição direta para os dirigentes escolares, que respeite o direito de consulta e de participação da comunidade e suas lideranças e considere as especificidades históricas, culturais, sociais, políticas, econômicas e identitárias das comunidades quilombolas. A ausência desses mecanismos de participação pode inviabilizar a consolidação de mecanismos de participação e democratização da gestão escolar e o fortalecimento da autonomia da escola.

A concepção do Conselho Escolar sobre a gestão democrática, não esgota aqui, tais análises nos apontam para a necessidade de ampliar a pesquisa sobre a gestão democrática no contexto da Educação Escolar Quilombola, sobretudo as políticas públicas de ações afirmativas para a Educação Escolar Quilombola e a ação do Conselho Escolar frente ao gerenciamento, monitoramento desses recursos, participação efetiva da comunidade nesse processo, seus entraves e conflitos. 
DOI: $10.12957 /$ teias.2021.52781

\section{REFERÊNCIAS}

BRASIL. Constituição da República Federativa do Brasil. Brasília, DF: Senado Federal/Centro Gráfico, 1988.

BRASIL. Ministério da Educação. Lei de Diretrizes e Bases da Educação Nacional, nº 9.394/1996. Brasília: Senado Federal, 1996.

BRASIL. Ministério da Educação. Secretaria de Educação Básica. Diretoria de Currículos e Educação integral. Diretrizes Curriculares Nacionais Gerais da Educação Básica. Brasília: MEC/SEB/DICEI, 2013.

BRASIL. Ministério da Educação. Secretaria Especial de Políticas de Promoção da Igualdade Racial Plano Nacional de Implementação das Diretrizes Curriculares Nacionais para as Relações ÉtnicoRaciais e para o Ensino de História e Cultura Afro-Brasileira e Africana. Brasília: MEC/SECADI/SEPPIR, 2009.

BRASIL. Conselhos Escolares: democratização da escola e construção da cidadania. Programa Nacional de Fortalecimento dos Conselhos Escolares. Brasília: PRONAF/CE, 2004.

BRASIL. Ministério da Educação. DCN para a Educação Escolar Quilombola. Diretrizes Curriculares Nacionais da Educação Básica. Brasília: CNE/CEB, 2010, p.425-495.

BRASIL. Diretrizes Curriculares Nacionais para a Educação das Relações Étnico-raciais e para o Ensino de História e Cultura Afro-brasileira e Africana. Brasília, DF: MEC, 2004.

BAILE, Stanley. Dinâmicas raciais no Brasil contemporâneo: uma revisão empírica. Revista do Programa de Pós-Graduação em Sociologia da USP, São Paulo, v.23.1, 2016, p.53-74.

CAVALLEIRO, Eliane (org.). Racismo e antir-racismo na educação: repensando na escola São Paulo: Selo Negro, 2001.

COELHO. Wilma de Nazaré Baía et al. Educação, História e Relações Raciais: debates em perspectiva. São Paulo: Editora da Física, 2015, v. 1, p. 99-136.

DOURADO, Luiz Fernandes (org.). Gestão da educação escolar. Ministério da Educação. Secretaria de Educação Básica. Brasília: UNB/CED, 2006.

FURTADO, Marcella Brasil; PEDROZA, Regina Lucia Sucupira; ALVES, Cândida Beatriz. Cultura, identidade e subjetividade quilombola: uma leitura a partir da Psicologia Cultural. In: Psicologia \& Sociedade, 26(1), 106-115. Brasília: UnB, 2014.

GOMES, Nilma Lino. Diversidade cultural, currículo e questão racial: desafios para a prática pedagógica. In: ABRAMOWICZ, Anete; BARBOSA, Maria de Assunção; SILVÉRIO, Valter Roberto (orgs.). Educação como prática da diferença. Campinas: Armazém do Ipê, 2006.

GOMES, Nilma Lino. Ações afirmativas: dois projetos voltados para a juventude negra. In: SILVA, Petronilha Beatriz Gonçalves e; SILVÉRIO Silva e Valter Roberto (orgs.). Educação e ações afirmativas: entre a injustiça simbólica e a injustiça econômica. - Brasília: Instituto Nacional de Estudos e Pesquisas Educacionais Anísio Teixeira, 2003

GRACINDO, Regina Vinhaes (org.). Gestão democrática nos sistemas e na escola. Brasília: UNB, 2007.

LIBÂNEO, José Carlos. Organização e gestão da escola: teoria e prática. São Paulo: Heccus Editora, 2015.

LIBÂNEO. Educação Escolar: políticas, estrutura e organização. São Paulo: Cortez, 2012

ORLANDI, Eni P. Análise de discurso: princípios e procedimentos. Campinas: Pontes, 2001.

PARO, Vitor Henrique. Gestão democrática da escola pública. São Paulo: Ed. Cortez, 2016. 
DOI: $10.12957 /$ teias.2021.52781

SEVERINO, Antônio Joaquim. Metodologia do trabalho científico. São Paulo: Cortez, 2007.

\section{Informações das autoras}

Raquel Amorim dos Santos

UFPA

E-mail: rakelamorim@yahoo.com.br

ORCID: https://orcid.org/0000-0003-4817-0036

Link Lattes: http://lattes.cnpq.br/3387666784015912

Rosângela Maria de Nazaré Barbosa e Silva

FAESA/ES

E-mail: rosangelabarbosaesilva@gmail.com

ORCID: https://orcid.org/0000-0001-8365-8067

Link Lattes: http://lattes.cnpq.br/7496714450612714

Valdecira Carvalho Silva

ORCID: https://orcid.org/0000-0003-4817-0036

Link Lattes: http://lattes.cnpq.br/1975410301717293 